\title{
FLUORIDE RELEASING CAPACITY OF NEWLY DEVELOPED ATRAUMATIC RESTORATIVE TREATMENT (ART) MATERIAL- AN IN-VITRO STUDY
}

\author{
Divya Kumari P1, Shahnawaz Khijmatgar², Avidyuti Chowdhury33, Lynch Edward4, Grootveld Martin 5 , Chitta Ranjan Chowdhury 6 \\ ${ }^{1}$ PhD Scholar, Department of Oral Biology and Genomic Studies, A. B. Shetty Memorial Institute of Dental Sciences, Nitte University, \\ Mangalore, Karnataka, India. \\ ${ }^{2}$ Lecturer, Department of Oral Biology and Genomic Studies, A. B. Shetty Memorial Institute of Dental Sciences, Nitte University, \\ Mangalore, Karnataka, India. \\ ${ }^{3}$ Researcher, King's College, London, Global Child Health Fund, England. \\ ${ }^{4}$ Professor of School of Dental Medicine, University of Nevada, Las Vegas, USA. \\ 5 Professor, Department of Bioanalytical Chemistry and Chemical Pathology, Health and Life Sciences, Leicester School of Pharmacy \\ Biomedical \& Environmental Health, De Montfort University, The Gateway, Leicester, \\ 6 Professor and Head of Department of Oral Biology and Genomic Studies, A.B. Shetty Memorial Institute of Dental Sciences, \\ Nitte University, Deralakatte, Mangalore, Karnataka India.
}

\section{BACKGROUND}

Fluoride ion-releasing Atraumatic Restorative Treatment (ART) materials are effective in the prevention of secondary caries. Hence, we have developed new and cost-effective ARTs.

The objective of this study is to assess the fluoride releasing capacity of two newly developed Atraumatic Restorative Treatment (ART) materials.

\section{MATERIALS AND METHODS}

Deionized water and freshly prepared artificial saliva were employed to estimate the level of fluoride ion released by two newlydeveloped atraumatic restorative treatment materials (ART-I and ART-II). The release of fluoride anion (F-) released at time-points of 1.0, 24, 168, 360, 720 and 1,440 hrs. were monitored by using an F-Ion-Selective Electrode (ISE) in both media. Statistical analysis was performed using a fixed-effects ANOVA model, together with polynomial and logistic regression approaches.

\section{RESULTS}

Fluoride release in deionized water: The mean F- released from ART-I material was $9.8 \mathrm{ppm}$ after $1 \mathrm{hr}$., which increased to a maximum of $40.5 \mathrm{ppm}$ after $168 \mathrm{hrs}$. However, the F- released by the ART-II material was $15.7 \mathrm{ppm}$ after $1.0 \mathrm{hr}$. and $52.7 \mathrm{ppm}$ at the $168 \mathrm{hrs}$. time-point. Fluoride release in artificial saliva: F- released from the ART-I material was found to be $6.5 \mathrm{ppm}$ after 1.0 hr. and $48.0 \mathrm{ppm}$ at $168 \mathrm{hrs}$. For ART-II, the F- released was $16.12 \mathrm{ppm}$ after $1 \mathrm{hr}$. a value increasing to a maximum of $35.0 \mathrm{ppm}$ at $168 \mathrm{hrs}$.

\section{CONCLUSION}

Both the ART-I and II biomaterials were found to release F- throughout the physiologically-relevant study time-periods incorporated within the experimental design.

\section{KEY WORDS}

Atraumatic Restorative Treatment Material (ART), Glass Ionomer Cement (GIC), Fluoride Releasing Capacity, Deionized Water, Artificial Saliva.

HOW TO CITE THIS ARTICLE: Kumari DP, Khijmatgar S, Chowdhury A, et al. Fluoride releasing capacity of newly developed Atraumatic Restorative Treatment (ART) material- an in-vitro study. J. Evolution Med. Dent. Sci. 2018;7(30):3423-3429, DOI: $10.14260 /$ jemds/2018/772

\section{BACKGROUND}

Dental caries is a multifactorial disease, which damages tooth structure and results in the formation of cavities within hard tissues such as enamel, dentine and cementum. The conventional treatment for dental caries is removal of decayed hard tissues via drilling with an aerator followed by restoration with a suitable filling material such as amalgams, composites and glass ionomers, etc.

'Financial or Other Competing Interest': None.

Submission 16-06-2018, Peer Review 10-07-2018,

Acceptance 16-07-2018, Published 23-07-2018.

Corresponding Author:

Chitta Ranjan Chowdhury,

Professor, Department of Oral Biology and Genomic Studies,

A. B. Shetty Memorial Institute of Dental Sciences,

Deralakatte, Nitte University, Mangalore, Karnataka, India.

E-mail:crc.ob.cod@gmail.com

DOI: $10.14260 /$ jemds $/ 2018 / 772$

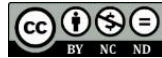

Many patients avoid dental treatment in view of the pain and discomfort, commonly experienced with conventional cavity preparation with dental drilling episodes.[1]

In order to overcome the limitations of conventional restorative treatment, Atraumatic Restorative Treatment materials (ARTs) were introduced in 1985, mainly for treating caries amongst children from under-served areas.[2] ART represents a minimal intervention approach and is recommended by the World Health Organisation. [3] The ART technique involves the removal of soft, demineralised tooth tissue using only hand-held instruments (such as an excavator, a process which forgoes the use of any drilling facilities) followed by filling the cavity with an adhesive dental restorative material (ART). This treatment is convenient and can be administered/ rendered by a primary healthcare provider. ${ }^{[4,5]}$ 
Several materials are used for ART restoration and examples include glass ionomer cements (GIC, e.g. Fuji IX), which has anti-cariogenic properties in view of their fluoride ion (F-)-releasing capacities. These materials are highly recommended by the WHO, especially for under-served communities.[6]

Since F- ion-releasing ART materials are effective in the prevention of secondary caries,[7-9] in this study we have developed new and cost-effective ARTs. In this context, determinations of the F-releasing capacity of new ART materials is of much important. Therefore, the major objective of this study was to monitor the F-releasing capacity of two newly-developed ART materials.[9]

\section{MATERIALS AND METHODS}

\section{Sample Preparation}

A total of 12 samples were prepared for each of two different ART compositions, ART-I and ART-II [Table 1]. Each composition was prepared and placed in a disc-shaped mould measuring $7 \mathrm{~mm} \times 3.5 \mathrm{~mm}$. The mould filled with these samples was primarily retained at ambient (room) temperature for 15 mins. and then stored in an environment with $100 \%$ relative humidity for a period of $24 \mathrm{hrs}$.

Two medias were employed: Deionized water and artificial saliva. Six samples were maintained in deionized water and the remaining 6 were maintained in artificial saliva. These matrices were then equilibrated at a temperature of $37^{\circ} \mathrm{C}$ in order to determine their fluoride releasing capacities in these two media; aliquots of these media were collected at time-points of $1.0,24,168,360,720$ and 1,440 hrs. In order to avoid contamination from further sources, all the samples and vials were washed with deionized water and then air-dried prior to changing the storage medium. A dust-free air-conditioned laboratory was maintained.

\section{Preparation of TISAB II Solution}

TISAB II solutions were prepared via the addition of $30.0 \mathrm{~g}$ of sodium hydroxide, $4.00 \mathrm{~g}$ of CDTA, $57.0 \mathrm{~mL}$ of glacial acetic acid and $58.0 \mathrm{~g}$ of sodium chloride in $1.00 \mathrm{~L}$ of deionized water.

The purpose of adding the TISAB II chelating reagent was to maintain constant $\mathrm{pH}$ and ionic strength values and also to circumvent the formation of fluoride complexes with trace metal ion contaminants. The $\mathrm{pH}$ of TISAB II solution was maintained between values of 5.0 to 5.5 .

\section{Fluoride Estimation}

Each sample was then placed in $10 \mathrm{~mL}$ storage solutions (i.e. 6 samples in deionized water and 6 samples in artificial saliva of two different compositions each) and stored at $37^{\circ}$ Celsius temperature. The samples were rinsed with $2 \mathrm{~mL}$ of deionized water and transferred to fresh $10 \mathrm{~mL}$ storage solutions at different time intervals. Aliquots of $2.5 \mathrm{~mL}$ of each storage solution were mixed with $2.5 \mathrm{~mL}$ of TISAB II.

The fluoride ion estimation was done by using an ion specific electrode (ELIT 9801, NICO 2000 Ltd., UK) with a single junction $0.1 \mathrm{M} \mathrm{AgCl}$ reference electrode. Using standard solution of sodium fluoride (NaF) mixed with equal volume of TISAB II, a calibrated graph was obtained. The millivolt $(\mathrm{mV})$ reading for the samples was taken to determine the fluoride concentration from the calibration graph.

Before measuring fluoride, two vials containing artificial saliva and deionized water with TISAB II in the ratio of 1: 1 were tested to determine the baseline fluoride concentration of the mediums. The mean baseline concentration was subtracted from each concentration obtained from the samples. The system was calibrated prior to each evaluation with fluoride standard solution (NaF 1000, 100 and 10 ppm).

\section{Composition of Artificial Saliva Solution}

The composition of the artificial saliva medium employed in these studies was calcium chloride $(0.111 \mathrm{~g})$, sodium chloride $(2.05 \mathrm{~g})$, sodium acetate $(2.05 \mathrm{~g})$ and sodium dihydrogen phosphate $(0.156 \mathrm{~g})$ dissolved in a final volume of one litre of deionized water (final $\mathrm{pH}$ value 6.60).[10] The compositions of two proposed ART materials evaluated are outlined in Table1.

\section{Statistical and Non-Linear Regression Analyses of Experimental Datasets}

The experimental design for univariate analysis of the $\mathrm{F}$ concentration ([F-]) dataset involved an ANOVA model, which incorporated 3 factors and 8 primary sources of variation: (1) 'between-ART materials,' qualitative fixed effect at 2 levels $\left(\mathrm{A}_{\mathrm{i}}\right)$; (2) 'between-equilibration media,' also a qualitative fixed effect at two levels $\left(\mathrm{M}_{\mathrm{j}}\right)$; (3) the experimental sampling time-point, a fixed effect also treated as a qualitative variable for the purpose of this study in view of the non-linear relationship of experimental media $\mathrm{F}^{-}$concentrations on this parameter $\left(\mathrm{T}_{\mathrm{k}}\right)$; $(4,5$ and 6$)$ ART material $\mathrm{x}$ equilibration medium, ART material $\mathrm{x}$ time-point and equilibration medium $\mathrm{x}$ time-point first-order interaction components $\left(\mathrm{AM}_{\mathrm{ij}}, \mathrm{AT}_{\mathrm{ik}}\right.$ and $\left.\mathrm{MT}_{\mathrm{jk}}\right)$ respectively; (7) the ART material $\mathrm{x}$ equilibration medium $\mathrm{x}$ time-point second-order interaction one $\left(\mathrm{AMT}_{\mathrm{ijk}}\right)$. This experimental design is represented by equation,[1] in which $\mathrm{Y}_{\mathrm{ijk}}$ represents the (univariate) [F-] values observed, $\mu$ its overall population mean value in the absence of any significant, influential sources of variation and $\mathrm{e}_{\mathrm{ijk}}$ the unexplained error (residual) contribution. ANOVA was performed using the XLSTAT 2017 software package.

$Y_{i j k l}=\mu+A_{i}+M_{j}+T_{k}+A M_{i j}+A T_{i k}+M_{j k}+A M T_{i j k}+e_{i j k l}----[1]$

Non-linear regression analysis of the relationships between the amounts of F- released from the ART materials tested against time was also performed using XLSTAT 2017 software, as was cubic spline polynomial analyses of these time-dependent data. In view of replicate observations, the number of nodes in the cubic spline analysis was reduced from 36 to 7 .

\section{RESULTS}

Highly significant differences in equilibration media fluoride ion concentrations were found 'between-ART materials,' 'between-equilibration media' and 'between-experimental time-points' with our ANOVA model analysis ( $\mathrm{p}=10^{-9}$ for all these factors). Moreover, all first-order and the single ART materials $\mathrm{x}$ equilibration medium $\mathrm{x}$ experimental time-point second-order interaction components of variation were also 
highly significant (again $\mathrm{p}<10^{-9}$ for all except the ART material $\mathrm{x}$ equilibration medium one, for which $\mathrm{p}=1.51 \times 10$ ${ }^{9}$ ). These results are displayed in Figures 1, and hence the dependence of experimental media $\mathrm{F}^{-}$levels on each of the factors explored displays a high level of complexity [Table 2].

We explored the fitting of a large number of non-linear regression fitting functions including standard polynomial ones with linear, quadratic and cubic independent variable (time-point) ones and also exponential ones. The most effective fitting model function for each dataset was found to be that described by equation 1 , in which pr1, pr2, pr3, pr4, pr5 and pr6 represent constants for each model investigated and $x$ represents the independent (time-point) variable.

$\mathrm{y}=\operatorname{Exp}\left(\operatorname{pr} 1+\mathrm{x}^{*} \operatorname{pr} 2\right) /(\mathrm{x}+1)^{\wedge} \operatorname{pr} 3+\operatorname{Exp}\left(\operatorname{pr} 4+\mathrm{x}^{*} \operatorname{pr} 5\right) /(\mathrm{x} 1+$ $1)^{\wedge} \operatorname{pr} 6---[2]$

Plots of observed F- concentration versus that predicted from equation 2 were clearly linear and also confirmed an excellent agreement between these two parameters [Figure2]. $\mathrm{R}^{2}$ values for these fits were 0.9810 and 0.9661 for the ART-I and ART-II materials respectively equilibrated in artificial saliva and 0.9935 and 0.9976 for ART-I and ART-II materials respectively equilibrated in deionized water. For the artificial saliva equilibration medium, all parameters (pr1-pr6) were found to be highly statistically significant for the ART-I material, but only the pr1 and pr4 ones were for the ART-II one in this medium. However, for the deionized water medium, the pr2-pr6 parameters were highly statistically significant for the ART-I material, whereas all but pr5 were also significant for the ART-II material tested.

A marginally higher concentration of fluoride was released by ART-II (16.12 ppm after $1 \mathrm{hr}$.) in artificial saliva compared to deionized water (15.66 ppm, after $1 \mathrm{hr}$.). But, ART-I released higher amounts of Fluoride concentration ( $9.83 \mathrm{ppm}$ after $1.0 \mathrm{hr}$.) in deionized water than in artificial saliva (6.48 ppm after $1.0 \mathrm{hr}$.) [Table 3]. After day 7 (i.e. 168 hours), fluoride release capacity decreased till day 60 [Figure-1] for ART-I in both storage mediums and ART-II in deionized water

Cubic spline polynomial plots of released fluoride concentration against equilibration time. This analysis performed involved a piece-wise function of third-degree polynomials.[11]

Cubic spline analysis was employed to explore the complex polynomial relationships between released $\mathrm{F}$ - level and equilibration time. Indeed, this served as a powerful means of predicting such relationships [Figure 3].

\begin{tabular}{|c|c|c|c|}
\hline $\begin{array}{c}\text { Composition of } \\
\text { ART Material }\end{array}$ & $\begin{array}{c}\text { ART-I } \\
\text { (\%) }\end{array}$ & $\begin{array}{c}\text { ART-II } \\
\text { (\%) }\end{array}$ & Action \\
\hline Zinc Oxide & 20 & 20 & $\begin{array}{c}\text { Base of the } \\
\text { Cement }\end{array}$ \\
\hline Aluminium Oxide & 70 & 70 & $\begin{array}{c}\text { Base of the } \\
\text { Cement }\end{array}$ \\
\hline Hydrogenated rosin & 06 & 06 & Bonding Agent \\
\hline $\begin{array}{c}\text { Sodium Fluoride } \\
\text { (NaF) }\end{array}$ & 03 & 03 & Fluoride Agent \\
\hline \begin{tabular}{c} 
Neem extract \\
\hline Eugenol
\end{tabular} & 06 & 11.5 & $\begin{array}{c}\text { Antibacterial } \\
\text { Agent }\end{array}$ \\
\hline $\begin{array}{c}\text { Ethoxybenzoic Acid } \\
\text { (EBA) }\end{array}$ & 60 & 40 & Binding Agent \\
\hline \multicolumn{2}{|c|}{ Table 1. Composition of New ART Materials } \\
\hline \multicolumn{2}{|c|}{} \\
\hline \multicolumn{2}{|c|}{ Bonding Agent } \\
\hline
\end{tabular}

\begin{tabular}{|c|c|c|c|c|c|}
\hline \multicolumn{6}{|c|}{ Type I Sum of Squares Analysis } \\
\hline Source & DF & $\begin{array}{c}\text { Sum of } \\
\text { Squares }\end{array}$ & $\begin{array}{c}\text { Mean } \\
\text { Squares }\end{array}$ & $\mathbf{F}$ & $\operatorname{Pr}>F$ \\
\hline \begin{tabular}{|l|} 
Product \\
\end{tabular} & 1 & 789.7739 & 789.7739 & 578.3211 & $<0.000000001$ \\
\hline $\begin{array}{l}\text { Time } \\
\text { (hr.) }\end{array}$ & 5 & 18975.6618 & 3795.1324 & 2779.0298 & $<0.000000001$ \\
\hline Medium & 1 & 98.2329 & 98.2329 & 71.9322 & $<0.000000001$ \\
\hline $\begin{array}{c}\text { Product* } \\
\text { Time } \\
\text { (hr.) }\end{array}$ & 5 & 401.0735 & 80.2147 & 58.7382 & $<0.000000001$ \\
\hline $\begin{array}{l}\text { Product* } \\
\text { Medium }\end{array}$ & 1 & 58.5671 & 58.5671 & 42.8865 & 0.0000 \\
\hline $\begin{array}{c}\text { Time } \\
\text { (hr.) * } \\
\text { Medium }\end{array}$ & 5 & 1998.0188 & 399.6038 & 292.6145 & $<0.000000001$ \\
\hline $\begin{array}{l}\text { Product* } \\
\text { Time } \\
\text { (hr.) }{ }^{*} \\
\text { Medium }\end{array}$ & 5 & 1141.8791 & 228.3758 & 167.2308 & $<0.000000001$ \\
\hline
\end{tabular}

Table 2. Multifactorial ANOVA of Experimental F- Release Data

\begin{tabular}{|c|c|}
\hline $\begin{array}{c}\text { Biomaterial/ } \\
\text { Medium }\end{array}$ & $\begin{array}{c}\text { Estimated Maximal } \\
\text { Release Time-Point (hr.) }\end{array}$ \\
\hline ART-I/ AS & 98.9 \\
\hline ART-II/ AS & 89.3 \\
\hline ART-I/ DW & 84.5 \\
\hline ART-II/ DW & 75.9 \\
\hline $\begin{array}{c}\text { Table 3. Estimated Maximal Release Time-Point of F- for } \\
\text { each of the four ART materials explored in this } \\
\text { Investigation }\end{array}$ \\
\hline \multicolumn{2}{|c|}{}
\end{tabular}

AS- Artificial Saliva, DW- Deionized Water 


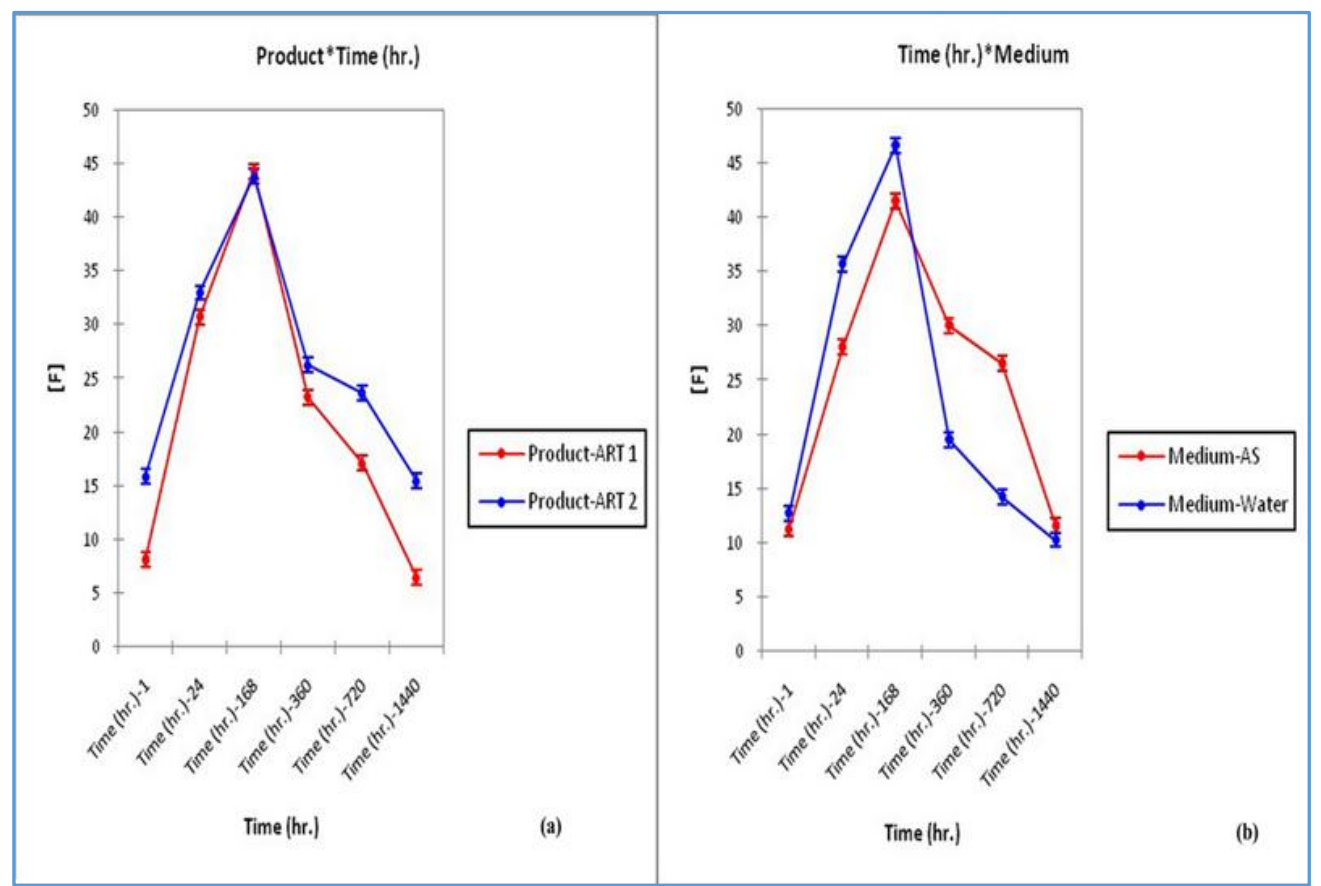

Figure 1. Fluoride releasing capacity by ART materials (a) with respect to Time and (b) in different media, AS-Artificial Saliva, Water- Deionized Water

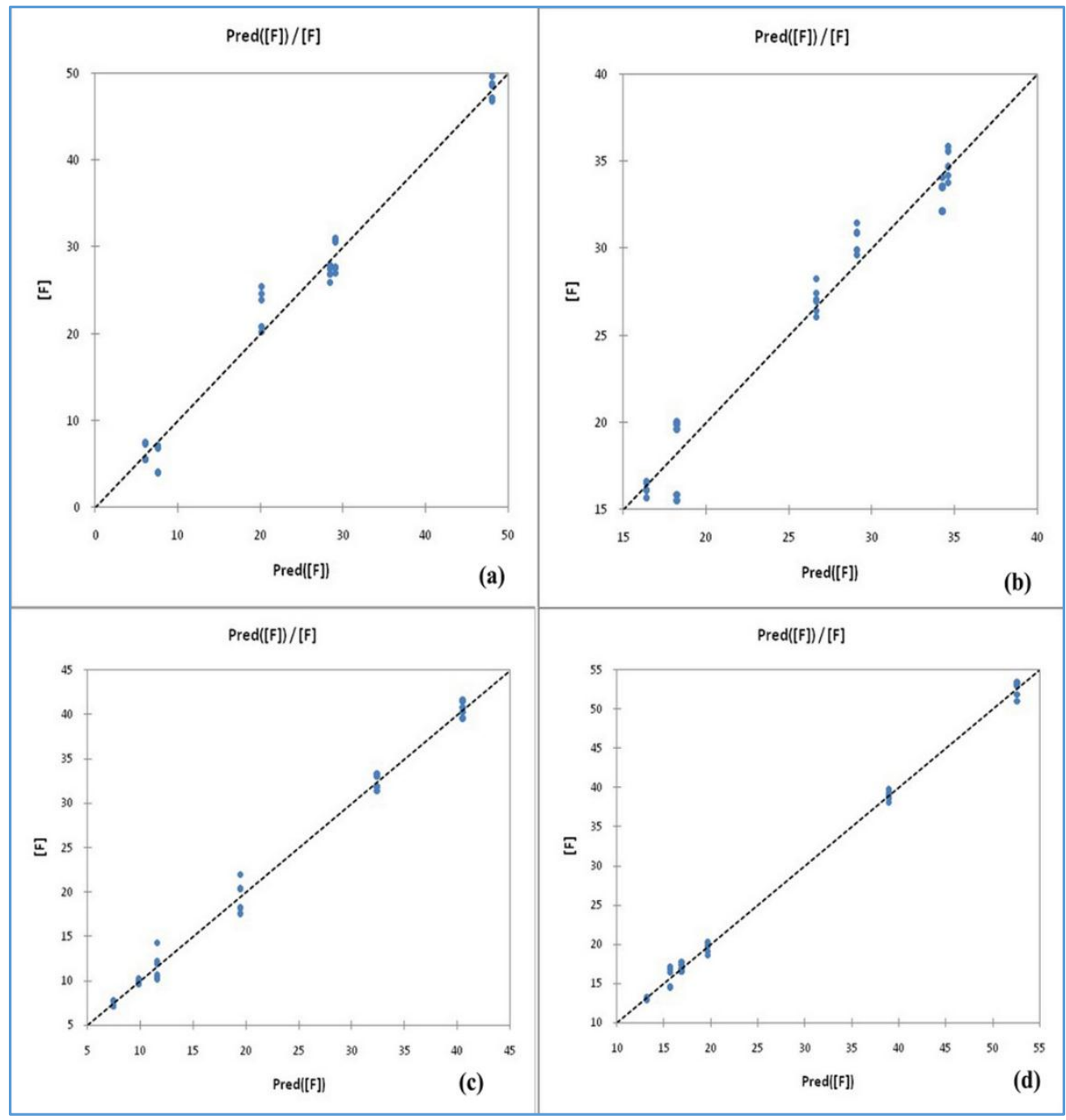

Figure 2. Plots of observed versus predicted F-concentration values for (a) ART-I material equilibrated in Artificial Saliva, (b) ART-II equilibrated in Artificial Saliva, (c) ART-I material equilibrated in Deionized Water and (d) ART-II material equilibrated in Deionized Water 


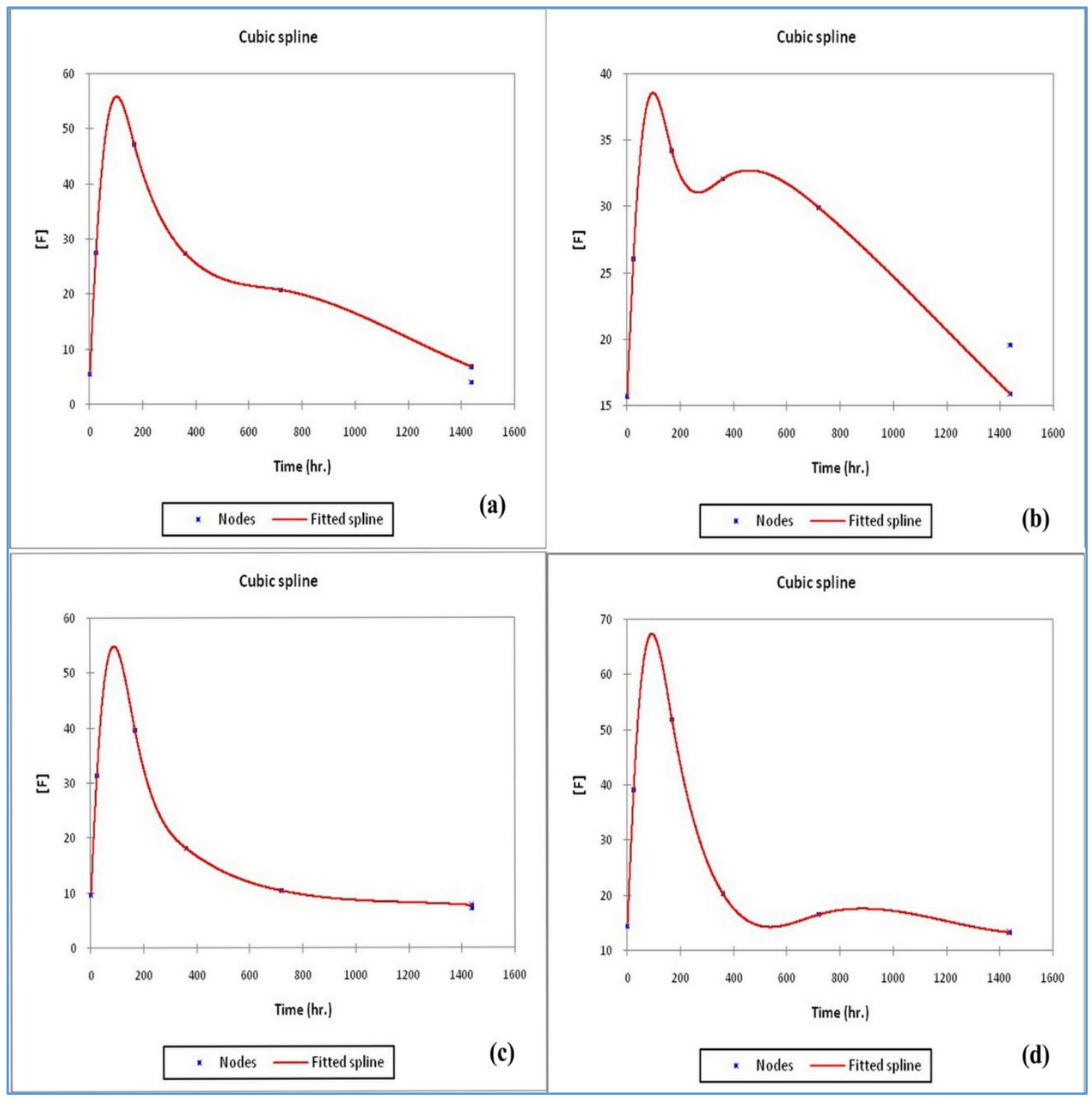

Figure 3. Cubic Spline Polynomial Plots of released fluoride by (a) ART-I-Artificial Saliva against equilibration time, (b) ARTII-Artificial Saliva against equilibration time, (c) ART-I-Deionized Water against equilibration time, (d) ART-II-Deionized Water against Equilibration Time

\section{DISCUSSION}

F-anion was introduced in dentistry seven decades ago, and is considered the most effective agent for the remineralisation of demineralised enamel. However, it is now well established that the aqueous form of $\mathrm{F}$ - is considered more effective than the fluoride present in the crystals of apatite, and has a cariostatic effect on carious lesions and healthy teeth exposed to it for prolonged time periods.[12]

Consequently, many restorative materials with fluoride releasing capacity have been developed. Several in vitro studies have revealed that $F^{-}$released from restorative materials protect the tooth cavity prepared for restoration.[13,14] The present study aimed to develop new ART materials and the $\mathrm{F}^{-}$releasing capacities of these represents a highly important phase of their physical property assessment in vitro. Indeed, the slow release of $\mathrm{F}$ serves as an essential property for any newly-developed ART material.

Both ART materials are differing in terms of concentration of Neem extract added to the material.[15]
Neem extract is extracted from the Neem plant parts by Soxhlet method.[16] Neem extract acts as the antibacterial agent added to the material to enhance its antibacterial property.[17]

Our study used deionized water and artificial saliva as release media with the former providing the baseline of $\mathrm{F}$ release ability under unsimulated conditions in accordance with previous studies.[18-22] In order to simulate the effect of natural human saliva, an artificial saliva medium was created and subsequently used as a second medium to employ in this investigation. The $\mathrm{F}^{-}$release from the materials tested into the medium depends on the diffusion of water into the material, its dissolution from the solid matrix followed by its diffusion into the aqueous phase utilised. Hence, we monitored these newly-developed ART biomaterials in two different dissolution media.

The results acquired demonstrated that the newlydeveloped ART-I and ART-II materials released F-, the amount released being critically time-dependent. However, 
we also observed a difference in the pattern of fluoride release for the two materials investigated with ART-II giving rise to higher levels of $\mathrm{F}^{-}$than ART-I in a saliva artificial medium, although it should be noted that ART-II released somewhat higher levels of F- than the ART-I material in a deionized water medium. The ability to release fluoride from both the materials gradually increased and reached to maximum after 168 hrs. [Figure 1]. Observations were consistent with those of previous investigations. ${ }^{[23,24]}$

The total cumulative fluoride released from both media by ART-II was found to be higher than that of ART-I, particularly at the shorter (0 - $24 \mathrm{hrs}$.) and lengthier (360 1,440 hrs.) time-points. However, these results contrast with those acquired in previous studies.[25] One of the reasons is the material strength of ART-II, which is lower than ART-I (The micro-hardness of ART-II was $20.4 \mathrm{VHN}$ and that of ART-I 35.4 VHN. The compressive strength of ART-II was 34.69 MPa and that of ART-I is $45.09 \mathrm{MPa}$ ). Materials with lower mechanical properties are known to release more fluoride into media. $[25,26]$

Comparisons of the concentrations of $\mathrm{F}^{-}$released into the two differing media employed showed that this was higher in deionized water initially for the first $24 \mathrm{hrs}$. in case of ART-I and the first $168 \mathrm{hrs}$. with ART-II. After this preliminary period, the $\mathrm{F}^{-}$level was in fact higher in artificial saliva for both ART-I and II, but also significantly lower for ART-II throughout the $168-1,440$ hrs. duration. Nonetheless, the highest concentration of fluoride recorded at the $168 \mathrm{hrs}$. time-point in deionized water was higher than that observed in the artificial saliva medium. This may arise since artificial saliva contains both cations and anions [i.e. it has a high ionic strength (I) when expressed relative to that of deionized water], which may exert a significant effect on the equilibrium between ART biomaterial matrix and solution phase F- levels. Indeed, anions present in the artificial saliva medium, which contained calcium chloride, sodium chloride, sodium acetate and sodium dihydrogen phosphate will be expected to suppress fluoride release from the ART materials tested. This is consistent with previous reports which demonstrated that glass-ionomer cements (GICs), i.e. Fuji IX, released more F- into deionized water than it did into artificial saliva.[19,27]

The percentage of fluoride released by the ART-I and ART-II materials during first 24 hrs. equilibrium period increased from $0.2 \%$ to $25 \%$ of the total cumulative fluoride released throughout the entire 1,440 hrs. experimental duration. However, throughout the 168 - 360 hrs. period, Frelease was substantially lower and thereafter gradually decreased at and from the $360 \mathrm{hrs}$. time-point. The results obtained clearly demonstrate that $\mathrm{F}^{-}$release occurs in two phases: a primary rapid release from the surface followed by a slower incremental release subsequent to the $168 \mathrm{hrs}$. timepoint. Hence, the first, relatively rapid phase of $\mathrm{F}$ - release is followed by a second bulk liberation of this anion via diffusion process, in which small quantities of it continues to be released into the media during the $360-1,440 \mathrm{hrs}$. period. Our data reflect those acquired in similar investigations performed by Tay and Braden (1988) and Verbeeck et al (1993).[28,29]

Irrespective of the medium employed, a number of previous studies have reported that F- released from resinmodified glass ionomers is greater than or similar to that from conventional glass ionomer materials.[8,25,26,30,31] Notwithstanding, other studies have reported that cementcontaining resin releases less fluoride to such media than non-resin restorative materials.[31-33] Both ART compositions evaluated here contains $6 \%(\mathrm{w} / \mathrm{w})$ hydrogenated resin. Indeed, these results are consistent with our observations, i.e. the total F- released from the ART-II composition in was greater than that of the ART-I material in both equilibration media utilised.

The rate of $\mathrm{F}$ - release from a restorative material in vivo can be affected by several factors such as temperature, salivary $\mathrm{pH}$ values, effective pre-mixing of ART material employed and its powder to liquid ratio.[29] And in vitro study, the factor influences the rate of fluoride release in ART materials are type of media, $\mathrm{pH}$ of media and composition of ART materials, surface area of materials expose to media, particle size of the materials, temperature and porosity.[22] However, the rate of F- release also appears to largely depend on clinical factors rather than the type of cement type applied. ${ }^{34,35]}$ For these studies, the temperature of the equilibration process was maintained at $37^{\circ} \mathrm{C}$ and the materials and F-specific ion-selective electrode was handled by a single operator.

\section{CONCLUSION}

1. Two newly-developed ART materials have the ability to release fluoride into both artificial saliva and deionized water, and the ART-II one was found to release higher levels of this agent into both artificial saliva and deionized water than did the ART-I composition;

2. The ART-I material was found to release marginally more $\mathrm{F}^{-}$at the 1.0 hour time-point in deionized water (9.828 ppm) than that detected in artificial saliva (6.48 ppm), although at $168 \mathrm{hrs}$., the F- released by this formulation was somewhat greater in artificial saliva than that observed in deionized water ( 48.0 ppm vs. 40.5 ppm respectively);

3. Similar concentrations of fluoride were released by the ART-II material into artificial saliva and deionized water at the $1.0 \mathrm{hr}$. time-point (16.1 vs. $15.7 \mathrm{ppm}$ respectively). No 'between-media' difference in the concentration of $\mathrm{F}$ released by the ART-II material was found. Overall, this may be considered as a valuable and effective property of the newly-developed ART material and reflects favourably on its efficacy for atraumatic restorative treatments.

\section{REFERENCES}

[1] Dorri M, Sheiham A, Marinho VC. Atraumatic restorative treatment versus conventional restorative treatment for the management of dental caries. Cochrane Database of Systematic Reviews 2009;(4):Art No.: CD008072.

[2] Frencken JE, Songpaisan Y, Phantumvanit P, et al. An Atraumatic Restorative Treatment (ART) technique: evaluation after one year. Int Dent J 1994;44(5):460-4.

[3] Jordan RA, Gaengler P, Markovic L, et al. Performance of Atraumatic Restorative Treatment (ART) depending on operator-experience. J Public Health Dent 2010;70(3):176-80. 
[4] Smales RJ, Yip HK. The Atraumatic Restorative Treatment (ART) approach for primary teeth: review of literature. Pediatr Dent 2000;22(4):294-8.

[5] Da Mata C, Allen PF, Cronin M, et al. Cost-effectiveness of ART restorations in elderly adults: a randomized clinical trial. Community Dent Oral Epidemiol 2014;42(1):79-87.

[6] Markovic DLj, Petrovic BB, Peric TO. Fluoride content and recharge ability of five glass ionomer dental materials. BMC Oral Health 2008;8:21.

[7] Garcia-Godoy F, Chan DC. Long-term fluoride release from glass ionomer-lined amalgam restorations. Am J Dent 1991;4(5):223-5.

[8] Basso GR, Bona DÁ, Gobbi DL, et al. Fluoride release from restorative materials. Braz Dent J 2011;22(5):355-8.

[9] Miranda LA, Weidlich P, Samuel SM, et al. Fluoride release from restorative materials coated with an adhesive. Braz Dent J 2002;13(1):39-43.

[10] Wiegand A, Buchalla W, Attin T. Review on fluoridereleasing restorative materials-fluoride release and uptake characteristics, antibacterial activity and influence on caries formation. Dent Mater 2007;23(3):343-62.

[11] Guillod T. Interpolations, courbes de Bézier et BSplines. Bulletin de la Société des Enseignants Neuchâtelois de Sciences 2008;(34):1-50.

[12] Cate TJM. In vitro studies on the effects of fluoride on de-and remineralization. J Dent Res 1990;69 Spec No.:614-9.

[13] Swartz ML, Phillips RW, Clark HE. Long-term F release from glass ionomer cements. J Dent Res 1984;63(2):158-60.

[14] Tam LE, Chan GP, Yim D. In vitro caries inhibition effects by conventional and resin-modified glassionomer restorations. Oper Dent 1997;22(1):4-14.

[15] Anusavice KJ, Shen C, Rawls HR. "Dental Cements." Phillips' Science of dental materials. $12^{\text {th }}$ edn. St. Louis, Mo: Elsevier/Saunders Health Sciences 2013: p. 30339.

[16] De Castro MDL, Garcia-Ayuso LE. Soxhlet extraction of solid materials: an outdated technique with a promising innovative future. Anal Chim Acta 1998;369:1-10.

[17] Lakshmi T, Krishnan V, Rajendran R, et al. Azadirachta indica: a herbal panacea in dentistry - an update. Pharmacogn Rev 2015;9(17):41-4.

[18] Temin SC, Csuros Z. Long-term fluoride release from a composite restorative. Dent Mater 1988;4(4):184-6.

[19] El Mallakh BF, Sarkar NK. Fluoride release from glassionomer cements in de-ionized water and artificial saliva. Dent Mater 1990;6(2):118-22.
[20] Geurtsen W, Bubeck P, Leyhausen G, et al. Effects of extraction media upon fluoride release from a resinmodified glass-ionomer cement. Clin Oral Investig 1998;2(3):143-6.

[21] Takahashi K, Emilson CG, Birkhed D. Fluoride release in vitro from various glass ionomer cements and resin composites after exposure to NaF solutions. Dent Mater 1993;9(6):350-4.

[22] Leung VW, Darvell BW. Artificial salivas for in vitro studies of dental materials. J Dent 1997;25(6):475-84.

[23] Mousavinasab SM, Meyers I. Fluoride release by glass ionomer cements, compomer and giomer. Dent Res J (Isfahan) 2009;6(2):75-81.

[24] Mungara J, Philip J, Joseph E, et al. Comparative evaluation of fluoride release and recharge of prereacted glass ionomer composite and nano-ionomeric glass ionomer with daily fluoride exposure: an in vitro study. J Indian Soc Pedod Prev Dent 2013;31(4):234-9.

[25] Gao W, Smales RJ. Fluoride release/uptake of conventional and resin-modified glass ionomers and compomers. J Dent 2001;29(4):301-6.

[26] Xu X, Burgess JO. Compressive strength, fluoride release and recharge of fluoride-releasing materials. Biomaterials 2003;24(14):2451-61.

[27] Cacciafesta V, Sfondrini MF, Tagliani P, et al. In-vitro fluoride release rates from 9 orthodontic bonding adhesives. Am J Orthod Dentofacial Orthop 2007;132(5):656-62.

[28] Tay WM, Braden M. Fluoride ion diffusion from polyalkenoate (glass-ionomer) cements. Biomaterials 1988;9(5):454-6.

[29] De Moor RJ, Verbeeck RM, De Maeyer EA. Fluoride release profiles of restorative glass ionomer formulations. Dent Mater 1996;12(2):88-95.

[30] Forsten L. Fluoride release and uptake by glassionomers and related materials and its clinical effect. Biomaterials 1998;19(6):503-8.

[31] Shaw AJ, Carrick T, McCabe JF. Fluoride release from glass-ionomer and compomer restorative materials: 6 month data. J Dent 1998;26(4):355-9.

[32] Grobler SR, Rossouw RJ, Van Wyk Kotze TJ. A comparison of fluoride release from various dental materials. J Dent 1998;26(3):259-65.

[33] Ferracane JL, Stansbury JW, Burke FJT. Self-adhesive resin cements-chemistry, properties and clinical considerations. J Oral Rehabil 2011;38(4):295-314.

[34] Davies EH, Sefton J, Wilson AD. Preliminary study of factors affecting the fluoride release from glassionomer cements. Biomaterials 1993;14(8):636-9.

[35] Vermeersch G, Leloup G, Vreven J. Fluoride release from glass-ionomer cements, compomers and resin composites. J Oral Rehabil 2001;28(1):26-32. 